\title{
PRODUTIVIDADE DE PLANTAS DE SOJA PROVENIENTES DE SEMENTES TRATADAS COM FÓSFORO ${ }^{1}$
}

\author{
FABRÍCIO BECKER PESKE ${ }^{2}$; LEOPOLDO BAUDET ${ }^{3}$ E SILMAR TEICHERT PESKE ${ }^{4}$
}

\begin{abstract}
RESUMO - O recobrimento de sementes possui potencial para tornar-se um fator de impacto no setor sementeiro, já que possibilita aderir uma vasta gama de materiais às sementes. Esta pesquisa teve como objetivo avaliar fontes e doses de fósforo aderidas às sementes de soja e recobertas por uma camada protetora de polímero. Foram usadas 4 doses de Fitina e de Fosfato bicálcico, sendo elas: 0,$0 ; 0,7 ; 1,4$ e 2,1 g/100g de semente. Os tratamentos foram avaliados em dois tipos de solo nos quais as plantas se desenvolveram: alta e baixa disponibilidade de fósforo, partindo-se de um solo com disponibilidade inicial de P de 10,5 mg dm-3, na qual em um solo houve correção de fertilidade com 60 kg ha-1 de super fosfato triplo, e em outro não, respectivamente. O polímero utilizado para o recobrimento foi aplicado na dose de $0,8 \mathrm{~mL} / 100 \mathrm{~g}$ de sementes. O delineamento experimental foi em blocos casualizados com 3 repetições, sendo as unidades experimentais dispostas em vasos com capacidade para $12 \mathrm{~L}$, utilizando-se 3 plantas por vaso. Os parâmetros avaliados foram: número de sementes por planta, massa de sementes por planta e peso de mil sementes. O recobrimento de sementes de soja com fósforo aumenta a produtividade, dependendo das fontes e doses de fósforo usadas. A dose de 21 gramas de Fitina por 1 kilo de sementes aumenta a produtividade da cultura da soja em mais de $14 \%$.
\end{abstract}

Termos para indexação: Glycine max, revestimento, macronutriente, produtividade.

\section{YEILD OF SOYBEAN PLANTS DERIVED FROM SEEDS COATED WITH PHOSPHORUS}

\begin{abstract}
It allows farmers to add a vast variety of materials to the seed. This project had the objective of studying the effects of sources and doses of phosphorous added to the soybean seed by coating. It involved four doses of phytic acid and bicalcic phosphate, which were: $0.0 ; 0.7 ; 1.4$ and $2.1 \mathrm{~g} / 100 \mathrm{~g}$ seeds. The treatments were evaluated in two types of soil: high and low phosphorous availability, obtained from a soil with initial P content of $10.5 \mathrm{mg} \mathrm{dm}-3$, in which in one type of soil $60 \mathrm{~kg}$ ha- 1 of super triple phosphate was applied while nothing was applied to correct the P content in the other soil. The polymer used in seed coating was applied at $0.8 \mathrm{ml} / 100 \mathrm{~g}$ of seeds. A randomized complete block design was used with three replications. It was used vases with $12 \mathrm{~L}$ of capacity with three plants per experimental units. The following parameters were evaluated: number of seeds per plants, weight of seeds per plants and the weight of a thousand seeds.. It was concluded that seed coating of soybeans seeds with
\end{abstract}

${ }^{1}$ Submetido em 03/07/2008. Aceito para publicação em 19/01/2009. Parte da Dissertação de Mestrado do primeiro autor apresentada a FAEM/ UFPEL.

${ }^{2}$ Eng. Agr., pós graduado no Departamento de Fitotecnia, FAEM/UFPEL. fpeske@yahoo.com.br

${ }^{3,4}$ Eng. Agr., Ph.D., Professor Titular, Departamento de Fitotecnia, FAEM/ UFPEL. Caixa Postal 354, 96010-900, Pelotas, RS. E-mail: lmbaudet@ gmail.com, peske@ufpel.edu.br. 
phosphorous increased productivity according to doses and phosphorous sources. The dosage of 21 grams of phytic acid per 1 kilo of seeds increased the yield by more than $14 \%$.

Index terms: Glycine max, seed coating, macronutrient, yield

\section{INTRODUÇÃO}

A semente é o ponto de partida para se ter um estande de plântulas uniforme e uma lavoura com elevado potencial de produtividade. O desenvolvimento normal e vigoroso da semente é o ponto chave quando se trata de precisão e eficiência, o qual pode culminar em uma planta com alto desempenho produtivo, ou, se pouco valorizada pelo agricultor, culminar em semente deteriorada no solo.

Sendo a soja a cultura mais cultivada no país, é uma das grandes responsáveis pelo desempenho econômico brasileiro. Porém, sua produtividade oscila de ano a ano e de região a região, devido a diversos fatores como: deficiência hídrica, doenças, pragas, fertilidade do solo, dentre outros.

Em termos de fertilidade, o macronutriente fósforo é, talvez, o elemento mais estudado e sobre o qual mais se escreve. Os motivos são vários: a importância para a vida da planta, do animal e do homem que se alimenta da planta transformada e a freqüência com que limita a produção, particularmente nos trópicos (Sanchez e Salinas, 1981).

São várias as funções que o fósforo desempenha nas plantas. Participa dos processos metabólicos, da transferência de energia, da fase inicial das partes reprodutivas, do desenvolvimento radicular e da formação de frutos e sementes ( Raij, 1991 ). Segundo Schachtman (1998), o fósforo participa com cerca de $2 \mathrm{~g} \mathrm{~kg}^{-1}$ do peso da matéria seca. Sendo que em soja, há uma imobilização média de $20 \mathrm{~kg} \mathrm{ha}^{-1}$ de fósforo em toda sua biomassa (Novais et al., 2007)

Em um experimento repetido por dois anos seguidos, Coutinho etal.(1991), constataram aumentos deprodutividade na cultura da soja superiores em até $100 \%$ em relação à testemunha, tanto com superfosfato triplo, termofosfato magnesiando e fosfato natural de gafsa.

O fosfato de reserva da planta está na forma de Fitina nas sementes e frutos e, na forma inorgânica, nos tecidos vegetativos (Butler e Jones, 1973). A concentração de fósforo fítico em sementes de cereais é relativamente alta, representando cerca de $70 \%$ a $80 \%$ do fósforo total, enquanto que em leguminosas, esse valor não ultrapassa 50\% (Common, 1940). Nas plantas deficientes, são principalmente os níveis de fósforo das reservas que decrescem (Mengel e Kirkby, 1987). Segundo, Cohen ( 1975 ), a relação entre fosfato inorgânico e fosfato orgânico reduz à medida que a planta envelhece. Segundo Mukherji et al. ( 1971 ), a degradação dos fitatos, realizado por fitases, conduz à um rápido declínio no fósforo ligado ao fitato durante a germinação de sementes de arroz, diminuindo de 2,67 à $0,80 \mathrm{mg}$ de fósforo / g de matéria seca em menos de 72 horas.

A evolução do acúmulo de fósforo em sementes de soja em desenvolvimento, assim como, a relação entre a quantidade de ácido fítico e fósforo totais contidas nas sementes, foi determinada por Rabov e Dickinson (1987). O ácido fítico foi detectado já na embriogênese e seu acúmulo progrediu linearmente à medida que a semente se desenvolvia. Quase todo o fósforo translocado para as sementes em desenvolvimento foi incorporado como ácido fítico, desde a terceira semana após o florescimento até a maturação fisiológica, tendo a soma dos demais compostos de fósforos permanecendo constante.

A descoberta de uma tecnologia que permita adubar a cultura de maneira mais precisa e eficiente, certamente não seria menosprezada por qualquer produtor aberto a novidades capazes de influenciar positivamente no seu ganho econômico. Entre os avanços mais promissores está a indústria de polímeros que vêm se desenvolvendo muito rápido e agressivamente nos últimos anos, principalmente na produção de produtos compatíveis com as formulações do tratamento convencional de sementes. O interesse pelos polímeros e corantes é fundamentado pelo uso cada vez maior de variedades de alto valor, proporcionando ao agricultor sementes de alta qualidade em destaque pela sua beleza e desempenho. ( Baudet e Peske, 2007 ).

O objetivo do presente trabalho foi estudar a eficiência da aplicação do macronutriente fósforo à semente de soja, verificando ao mesmo tempo doses e fontes do elemento aplicado através do processo de recobrimento. 


\section{MATERIAL E MÉTODOS}

Foram realizados testes exploratórios envolvendo o processo de recobrimento no Laboratório Didático de Análise de Sementes da Universidade Federal de Pelotas (LDAS / UFPel). Os testes exploratórios tiveram o intuito de determinar em termos físicos, as quantidades máximas de fontes de Fósforo (Fitina e Fosfato Bicálcico) possíveis de serem aderidas pela camada de recobrimento com polímero às sementes, sem alterar seu formato e tamanho. A partir da dose máxima possível, determinou-se as demais doses do macronutriente a serem incluídas na pesquisa em questão.

Os tratamentos consistiram da aplicação de duas fontes externas de fósforo à semente (Fitina e Fosfato Bicálcico), com quatro doses cada uma ( 0,$0 ; 0,7 ; 1,4$ e $2,1 \mathrm{~g} / 100 \mathrm{~g}$ de sementes). Os tratamentos foram avaliados em solo corretamente corrigido com fósforo e não corrigido com fósforo.

O solo usado possuía baixos teores de matéria orgânica e argila, sendo que sua disponibilidade inicial de $\mathrm{P}$ era de $10,9 \mathrm{mg} \mathrm{L}^{-1}$. Para a diferenciação na fertilidade dos solos, um permaneceu com sua composição original e o outro recebeu uma complementação equivalente a $60 \mathrm{~kg} \mathrm{ha}^{-1}$ de Super Fosfato Triplo.

Foram utilizadas sementes de soja da cultivar CD 202, produzidas na safra 2004/2005, e classificadas manualmente com o auxílio de peneiras, utilizando as sementes de tamanho entre 6,0 e 6,5 mm, com germinação foi $85 \%$, e vigor de $82 \%$ ( Teste de frio ).

O processo envolveu agitar 100 gramas de sementes no interior de um saco plástico junto à fonte de fósforo empregada em sua respectiva dose, a qual aderiu naturalmente às sementes sem adição de adjuvante, devido à natureza física de ambas as fontes de fósforo utilizadas nos tratamentos.

Após a aplicação das fontes de fósforo às sementes, procedeu-se ao recobrimento com o polímero PolySeed $\mathrm{CF}^{\circledR}$ da empresa Rigrantec de cor vermelha na dose de $0,8 \mathrm{ml} /$ $100 \mathrm{~g}$ de sementes. O propósito da utilização do polímero foi minimizar as perdas de fósforo ao manejar a semente durante o processo de semeadura, além de facilitar e uniformizar o tratamento das mesmas. O tratamento com polímero foi realizado com o auxílio de um saco plástico de primeiro uso, em que foi colocado o polímero, e uniformizado através da superfície interior deste saco, para posteriormente, as sementes tratadas com fósforo serem adicionas e recoberta pelo produto. Imediatamente após, as sementes foram secas por aeração artificial.
Foram semeadas 10 sementes de cada tratamento em vasos com capacidade de 12 litros $(0,45 \mathrm{~m}$ altura), localizados na horta pertencente à Faculdade de Agronomia Eliseu Maciel, no Capão do Leão - RS, na safra 2005/06. Após a emergência das plântulas ocorrida no quinto dia após semeadura, foi realizado desbaste deixando três plantas por vaso. A inoculação das sementes foi realizada empregando inoculante turfoso previamente à semeadura, sem danificar a camada de revestimento do polímero.

As avaliações consistiram na determinação dos seguintes componentes de produção:

a) Número de sementes por planta - determinado pela contagem do número de sementes nas três plantas por vaso;

b) Massa total de sementes por planta - determinado em gramas com duas casas decimais das sementes colhidas nas três plantas;

c) Peso de 1000 sementes - determinado em função da massa e número total de sementes por unidade experimental, ajustado para o peso de 1000 sementes.

O estudo consistiu de um arranjo fatorial (2x2x4) em blocos casualizados com 2 tipos de solo x 2 fontes de fósforo x 4 doses de fósforo, com três repetições, perfazendo 48 unidades experimentais. Colocou-se em blocos para melhor controle da variação ambiental do local do experimento.

A análise estatística foi realizada com o suporte do programa estatístico Winstat II. Os dados de doses foram submetidos à análise de variância através do teste de F a 5\% de probabilidade, e estudo de regressão polimonial.

\section{RESULTADOS E DISCUSSÃO}

Houve interação significativa da adubação do solo com a fonte de fósforo e as doses de fósforo para os parâmetros número de sementes por planta e peso total de sementes por planta. Assim, como a dose é uma variável quantitativa, utilizou-se de regressão polimonial para análise dos dados, em que para melhor visualização, fixou-se o tipo de solo e as duas fontes de fósforo foram apresentadas dentro de dosagens, como pode ser observado nas figuras de 1 a 4 . O parâmetro de avaliação de peso de 1000 sementes não apresentou significância.

Analisando o efeito de diferentes fontes de fósforo em quatro doses sobre o número de sementes por planta em solo com alta disponibilidade de fósforo, constatou-se um ajuste quadrático para o efeito de doses de Fitina no número de sementes por planta, em que o coeficiente de determinação de 0,99 explica quase a totalidade da variação 
(Figura 1). As doses até 1,4g / 100g de semente apresentaram respostas semelhantes, entretanto na dose mais alta de $2,1 \mathrm{~g}$ / 100 g de sementes observou-se um incremento acentuado, possibilitando afirmar que o efeito da Fitina no número de sementes por planta poderia ser ainda maior, com o uso de doses mais elevadas. O tratamento com Fitina, em sua maior dose produziu 108 sementes por planta em média, enquanto a testemunha apresentou 94 sementes por planta em média, superando-a em até 14 sementes por planta em média.

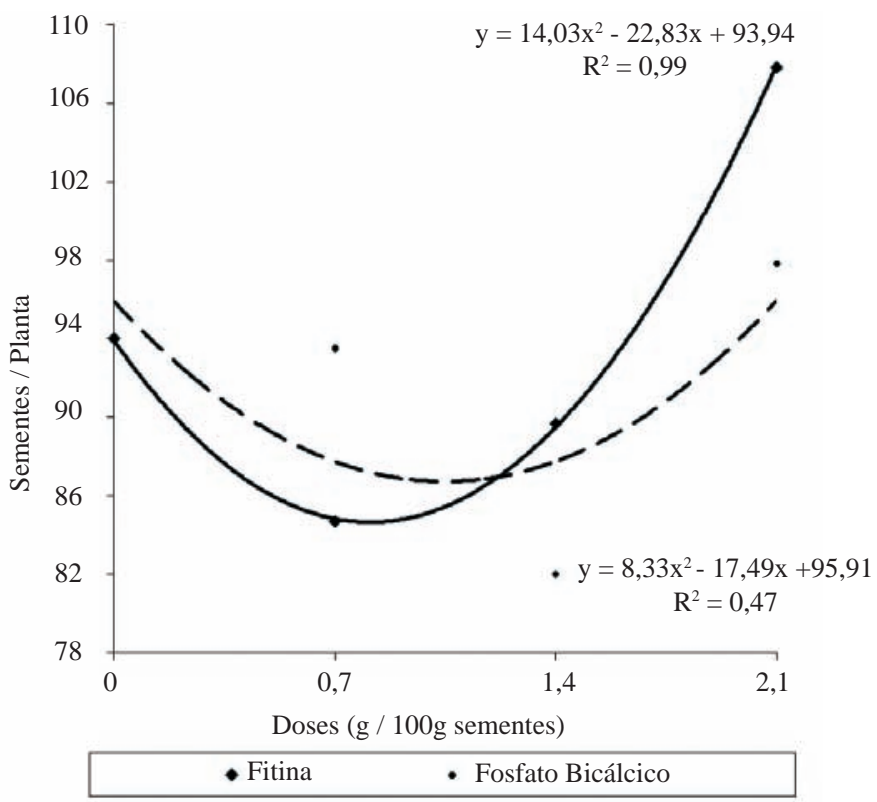

FIGURA 1. Número total de sementes por planta em função de fontes e doses de fósforo aplicadas nas sementes via recobrimento, em solo de alta disponibilidade de fósforo.

O efeito das doses de fósforo no número de sementes por planta utilizando Fosfato Bicálcico como fonte em solo com alta disponibilidade de fósforo, apresentou relação quadrática entre doses e número de sementes com um coeficiente de determinação de 0,47 (Figura 1). Isto evidencia que o efeito das doses de fósforo é dependente da fonte utilizada.

O número de sementes por planta em solo com baixa disponibilidade de fósforo (Figura 2) indica similaridade com os resultados obtidos em solo com alta disponibilidade do elemento, porém com valores inferiores. Analisando os dados, constata-se que o tratamento com a maior dose de Fitina superou a testemunha em 28 sementes por planta.

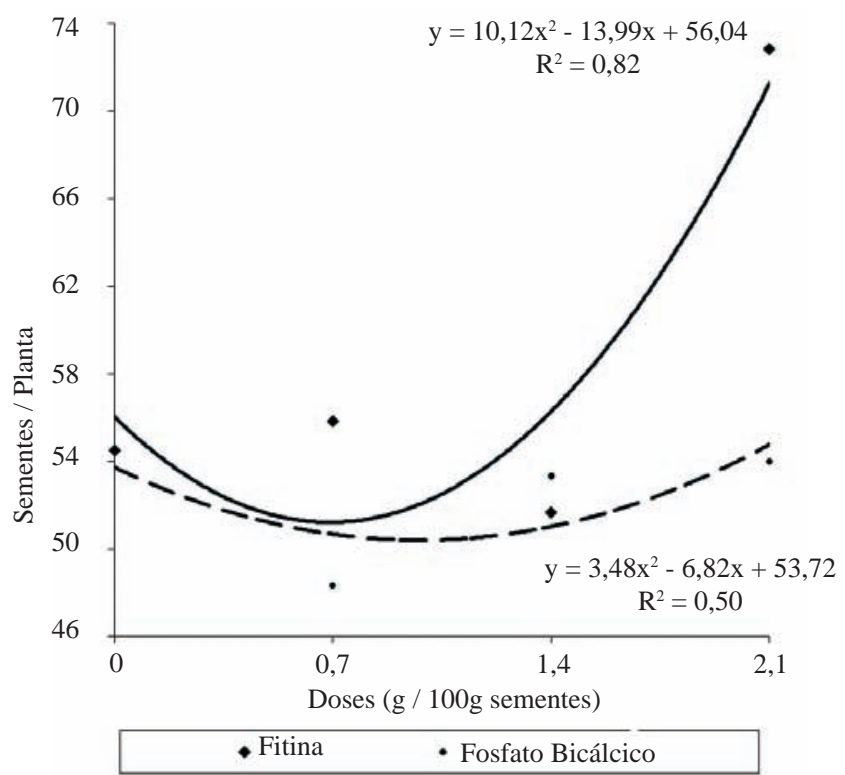

FIGURA 2. Número total de sementes por planta em função de fontes e doses de fósforo aplicadas nas sementes via recobrimento, em solo de baixa disponibilidade de fósforo.

Analisando os efeitos benéficos da Fitina na dose de 2,1g / 100 g de sementes nos dois tipos de solo, constatase por meio das Figuras 1 e 2, diferenças em relação a disponibilidade de fósforo no solo, uma vez que, no solo com alta disponibilidade de fósforo o incremento foi de $14 \%$ no número de sementes / planta, enquanto que no solo com menor disponibilidade de fósforo o incremento foi de $50 \%$.

Analisando a massa de sementes por planta em solo com alta disponibilidade de fósforo, constata-se que os tratamentos com Fitina ajustaram-se a uma equação quadrática em função de doses, sendo que a partir de 1,0g / 100g sementes, houve um acréscimo acentuado da massa de sementes por planta (Figura 3). Por outro lado, os efeitos dos tratamentos com Fósfato Bicálcico não foram positivos, apresentando também um baixo coeficiente de determinação.

Os tratamentos com Fitina a partir das doses de 1,4g / $100 \mathrm{~g}$ de sementes, apresentaram um aumento de produtividade por planta.

Os resultados obtidos na análise da massa total de sementes por planta em solo com baixa disponibilidade de fósforo (Figura 4) apresentam também para a Fitina um ajuste quadrático para as doses de fósforo. Contatou-se um incremento acentuado na massa de sementes por planta na dose de 2,1g / 100 g de sementes em relação às demais doses, que para efeitos práticos podem ser considerados 
iguais à dose zero a qual não recebeu fósforo externo. Este incremento foi de 2,1 gramas em peso total de sementes por planta, o qual considerando uma população de 250.000 plantas.ha- ${ }^{-1}$ atinge um aumento de $525 \mathrm{~kg} / \mathrm{ha}$. Em solo com menor disponibilidade de fósforo, as doses do tratamento com Fosfato Bicálcico não apresentaram resultados positivos em relação à testemunha.

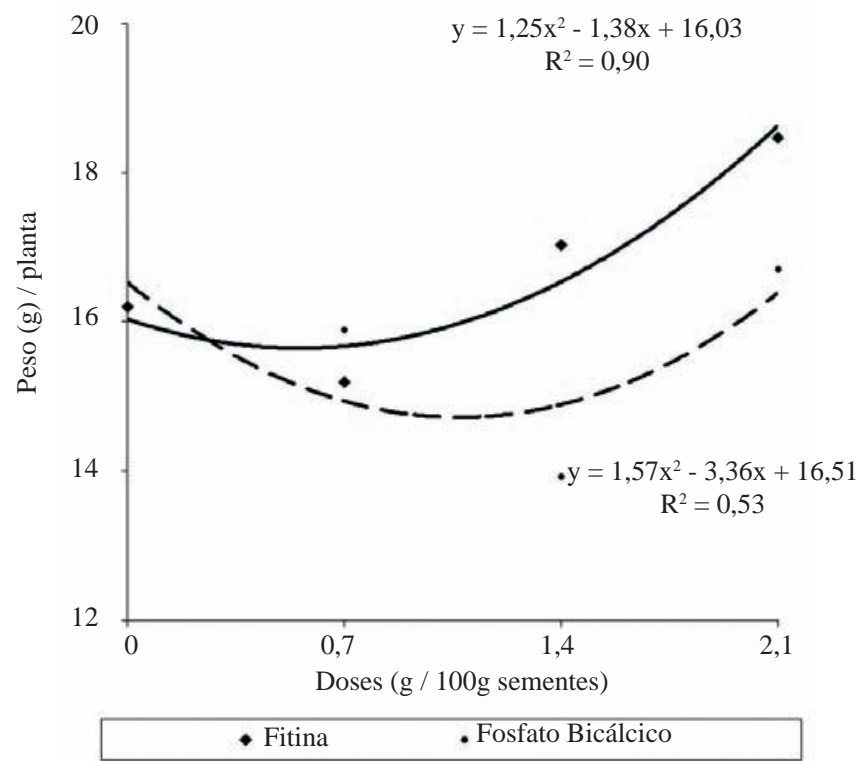

FIGURA 3. Produtividade de sementes de soja em função de fontes e doses de fósforo aplicadas nas sementes via recobrimento, em solo de alta disponibilidade de fósforo.

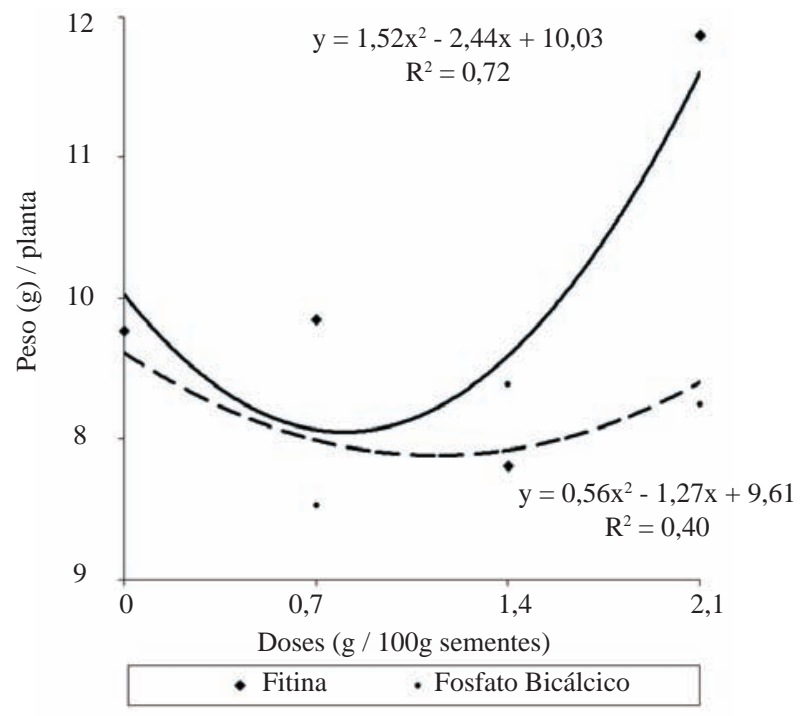

FIGURA 4. Produtividade de sementes de soja em função de fontes e doses de fósforo aplicadas nas sementes via recobrimento, em solo de baixa disponibilidade de fósforo.
Analisando a diferença percentual do efeito do recobrimento de sementes de soja com Fitina na dose de 2,1g / 100g de sementes, constata-se que em solo com maior disponibilidade de fósforo o incremento foi de 2,27 gramas por planta, significando um aumento de $14 \%$ em relação à dose zero, enquanto que o efeito da Fitina em solo com baixa disponibilidade do elemento, o aumento foi de 2,1 gramas por planta, representando um aumento de $17,7 \%$. Assim, muitas vezes os valores absolutos podem informar muito mais do que valores relativos, pois o acréscimo de $14 \%$ com uma massa de 2,27 gramas de sementes por planta significa um aumento por ha (considerando população de plantas de 250.000 plantas / ha) de 567,5kg, enquanto que o acréscimo de 17,7\% com uma massa de 2,1 gramas de sementes por planta, em solo com baixa disponibilidade de fósforo, significa um aumento de $525 \mathrm{~kg} / \mathrm{ha}$, portanto uma diferença de $42 \mathrm{~kg} /$ ha. Enfatiza-se que a inferência em relação aos possíveis ganhos por hectare podem neste caso serem superestimados, pois não se considerou as possíveis falhas que normalmente ocorrem nos campos de produção, afetando a distribuição das plantas e com isso diminuição da produtividade. Entretanto, em função dos dados obtidos por planta neste estudo, em que o máximo foi de 108 gramas, pode-se considerar que a inferência é válida.

O incremento de $50 \%$ no número de sementes em relação às sementes não tratadas, quando se utiliza sementes de soja recobertas com Fitina na dose de 2,1g / 100g de sementes em solo com baixa disponibilidade de fósforo, não é verificado na mesma proporção quando analisado o incremento da produtividade por planta que foi de $17,7 \%$.

Considerando que não houve significância estatística dos tratamentos no peso de 1000 sementes, em que a média geral foi 173,2 gramas, o aumento de produção constatado pelo recobrimento das sementes com Fitina é atribuído ao acréscimo do número de sementes por planta.

O Fosfato Bicálcico não apresentou efeito na produtividade tanto em solo de baixa com em alta fertilidade de fósforo, apresentando para as equações de segundo grau um coeficiente de determinação variando de 0,40 a 0,53 , ou seja, os dados explicam menos de $55 \%$ dos resultados e mesmo assim os valores estimados pelas equações não superaram ao da testemunha.

A aplicação de fósforo por meio do recobrimento em sementes de soja terá um benefício na produtividade de grãos. Este resultado coincide com os resultados obtidos por Trigo et al. ( 1997 ) trabalhando com fósforo já nos constituintes da semente, os quais afirmaram que o incremento da concentração de fósforo endógeno na semente de soja 
aumenta o potencial de rendimento da planta subseqüente. Este resultado é ainda confirmado por outros autores em relação a outras espécies de sementes como cenoura (Austin e Logden, 1966), feijão (Vieira,1986; Thomson et al.,1992) e tremoço (Boland e Baker,1989).

Resultados similares com aplicação externa de fósforo na semente também foram obtidos por Zelonka et al. (2005) com recobrimento de sementes de cevada e Rebafka et al. (1993 ) em sementes de milheto (Pennisetum glaucum (L.) $\mathrm{R}$. Br.) recobertas com fósforo e conduzidas em solo arenoso e ácido.

George et al. (1978) em tomate e Bhattacharyya et al. ( 1984 ) em Vigna Mungo, constataram resultados similares aos obtidos neste trabalho em que o fósforo aplicado ás sementes incrementam a produção. Enquanto que Thompson et al. ( 1992 ), ao realizarem pesquisas com tremoço, relataram que níveis inferiores de fósforo na semente acarreta menor produtividade.

Em relação aos benefícios do fósforo na semente em função da fertilidade do solo, constatou-se um aumento de 2,1 a 2,2g/planta, valores estes inferiores aos encontrados por Trigo et. al. (1997) em solos com maior disponibilidade de fósforo. $\mathrm{O}$ fósforo, dentro da semente ou aplicado em sua superfície, apresenta resultados benéficos, porém não substitui a correção do solo em caso de deficiência de fósforo.

A colocação de fósforo externo na semente irá propiciar à indústria de sementes a possibilidade de agregação de valor ao seu produto, ofertando ao agricultor a opção de adquirir sementes de soja recobertas com fósforo que poderá lhe propiciar um aumento de produtividade.

\section{CONCLUSÕES}

Sob as condições as quais esta pesquisa foi desenvolvida, os dados obtidos permitiram as seguintes conclusões:

O recobrimento de sementes de soja com fósforo aumenta a produtividade dependendo das fontes e doses do fósforo usadas;

A dose de 21 gramas de Fitina / kg de sementes aumenta a produtividade da cultura da soja em mais de $14 \%$ peso total de grãos.

\section{AGRADECIMENTOS}

Ao Programa de Pós - graduação em Ciência e Tecnologia de Sementes da Faculdade de Agronomia "Eliseu Maciel"/ Universidade Federal de Pelotas, por ter disponibilizado de todas as condições para a realização do experimento e ao
CNPq, o qual dispôs dos recursos financeiros.

\section{REFERÊNCIAS}

AUSTIN, R.B.; LOGDEN, P.C. The influence of the phosphorus and nitrogen nutrition of pea plants on the growth of the progeny. Plant and Soil, n. 24, p. 359-368, 1966.

BAUDET, L; PESKE, F; Aumentando o desempenho das sementes. Revista SEED News, v. 9, n.5, p. 22-24, 2007.

BHATTACHARYYA, K. K.; SENGUPTA, K.; CHATTERJEE, B. N. Seed treatment for increasing blackgram ( vigna mungo ) in rainfed agriculture. Seed Research, v. 12, p.40-47, 1984.

BOLAND, M.D.A.; BAKER, M.J. High phosphorus concentration in Trifolium balanceae and Medicago polymorpha seed increases herbage and seed yields in the field. Australian Journal of Experimental Agriculture, n.29, p.791-795, 1989.

BUTLER, G. W.; JONES, D. I. H. Mineral biochemistry of herbage. In: BUTLER, G. W. ; BAILEY, R. W. (Ed.). Chemistry and biochemistry of herbage. London: Academic Press, 1973. p. 127-162.

COHEN, R. D. H. Phosphorus and the grazing ruminant. World Review of Animal Production, v. 11, n. 2, p. 27-43, 1975.

COMMON, R. H. The phytic acid content of some poultry feeding stuffs. The Analyst, v. 65, n. 767, p. 79-82, 1940.

COUTINHO, E. L. M.; NATALE, W.; VILA NOVA, A. S.; SITTA, D. S. X.; Eficiencia agronômica de fertilizantes fosfatados para a cultura da soja. Pesquisa Agropecuária Brasileira, v.26, n.9, p.1393-1399, 1991.

GEORGE, R. A. T.; STEPHENS, R. J.; VARIS, S. Efecto de los nutrients minerals sobre el rendimiento y calidad de la semilla de tomate. In: HEBBLETHWAITE, P. D. Producción moderna de las semillas. Montevideo: Editorial Hemisfério Sur, 1978. p. $668-675$.

MENGEL, K.; KIRKBY, E. A. Principles of plant nutrition. 4. ed. Bern: International Potash Institute, 1987. 687 p.

MUKHERJI, S.; DEY, B.; PAUL, A. K. ; SIRCAR, S. M. Changes in phosphorus fractions and phytase activity of rice seeds during germination. Physiologia Plantarum, v.25, p.94-97, 1971.

NOVAIS, F. R.; ALVAREZ, V. H.; BARROS, N. F de.; FONTES, R. L.; CANTARUTTI, R. B.; NEVES, J. C. L. Fertilidade do solo. Viçosa: SBCS, 2007. 1017 p. 
RABOV, V.; DICKINSON, B. D.; The timing and rate of Phytic acid accumulation in developing soybean seeds. Plant Physiology, v.3, n.85, p.841-844, 1987.

RAIJ, B. van. Fertilidade do solo e adubação. São Paulo: Ceres; Piracicaba: Potafos, 1991. p.181-202

REBAFKA, F. P.; BATIONO A.; MARSCHNER H.; Phosphorus seed coating increases phosphorus uptake, early growth and yield of pearl millet (Pennisetum glaucum (L.) R. Br.) Journal Nutrient Cycling in Agroecosystems, v. 35, n. 3, p. 151-160, 1993.

SANCHES, P. A.; SALINAS, J. G. Low input technology for managing Oxisols in Tropical América. Advances in Agronomy, v. 34, p. 279-406, 1981.

SCHAHTMAN, D. P.; REID, R. J.; AYLING, S. M. Phosphorus uptake by plants: From Soil to Cell. Plant Physiology, v. 116, p. 447-453, 1998.

THOMPSON, J. R.; BELL, R. W.; BOLLAND, M. D
.A. Low seed phosphorous concentration depress early growth and nodulation of narrow - leafed lupin ( Lupinus angustifolius cv. Gungurro ). J. Plant Nutrition, v.15, n. 8, p. 1193 - 1214, 1992.

TRIGO, L. F. N.; PESKE, S. T.; GASTAL, M. F. C.; VAHL, L. C. TRIGO, M. F. O.; Efeito do conteúdo de fósforo na semente de soja sobre o rendimento da planta resultante. Revista Brasileira de Sementes, v. 19, n. 1, p.111-115, 1997.

VIEIRA, R.F. Influência de teores de fósforo no solo sobre a composição química, qualidade fisiológica e desempenho no campo de sementes de feijão (Phaseolus vulgaris L.). Revista Ceres, v.33, n.186, p. 173-188, 1986.

ZELONKA, L.; STRAMKALE, V.; VIKMANE, M.; Effect and after-effect of Barley seed coating with phosphorous on germination, photosynthetic pigments and grain yield. Acta Universitatis Lativiensis - Biology, v. 691, p. 111 - 119, 2005. 